\title{
Degradabilidade in situ da cana-de-açúcar tratada ou não com óxido de cálcio, em novilhas leiteiras Holandês x Gir
}

[In situ degradability of sugarcane treated or not with calcium oxide in Holstein x Gyr dairy heifers]

M.M. Campos ${ }^{1}$, A.L.C.C. Borges ${ }^{2}$, F.C.F. Lopes ${ }^{1}$, C.G. Pancoti ${ }^{3}$, R. Reis e Silva ${ }^{2}$

${ }^{1}$ Embrapa Gado de Leite - Juiz de Fora, MG

${ }^{2}$ Escola de Veterinária - Universidade Federal de Minas Gerais

${ }^{3}$ Aluno de pós-graduação - Escola de Veterinária - Universidade Federal de Minas Gerais - Belo Horizonte, MG

\section{RESUMO}

Avaliou-se a degradabilidade in situ da cana-de-açúcar in natura ou tratada por 24h com óxido de cálcio em diferentes porcentagens de inclusão na matéria natural da dieta, 0,$0 ; 0,5 ; 1,0$ e 2,0\%, no rúmen de cinco novilhas Holandês x Gir. Os parâmetros de degradação ruminal da matéria seca (MS), matéria orgânica (MO), fibra em detergente neutro (FDN) e fibra em detergente ácido (FDA) foram estimados ajustando modelo não linear aos dados de degradabilidade, sendo os parâmetros obtidos utilizados em análises de regressão linear e quadrática realizadas em função da inclusão do óxido de cálcio nas dietas. As degradabilidades potencial e efetiva e as taxas de degradação da MS e da MO aumentaram linearmente com o aumento de inclusão de $\mathrm{CaO}$. $\mathrm{O}$ aumento da porcentagem de inclusão de $\mathrm{CaO}$ em dietas à base de cana-de-açúcar aumentou linearmente a degradabilidade in situ da MS e da MO e não alterou a degradabilidade in situ das frações fibrosas.

Palavras-chave: bovino, álcali, hidrólise

\begin{abstract}
In situ degradability of sugarcane in natura or added to different levels of calcium oxide ( $\mathrm{CaO})$ in fed diet, $0.0 ; 0.5 ; 1.0$ and $2.0 \%$ for 24 h in five Holstein $x$ Gyr heifers, fitted with a rumen cannula.The parameters of rumen degradation of dry matter (DM), organic matter (OM), neutral detergent fiber $(N D F)$ and acid detergent fiber $(A D F)$ were estimated by adjusting non-linear model to data degradation, and used the parameters obtained in regression analysis, linear and quadratic performed according to the level of inclusion of calcium oxide in diets.The potential and effective degradability, as well as the degradation rates of DM and OM were lineraly enhanced with the increasing of the CaO levels in diet. The increasing levels of $\mathrm{CaO}$ in sugarcane diets offered to Holstein $x$ Gyr dairy heifers lead to a linear enhancement of in situ degradability of DM and OM, but does not affect the in situ degradability of fiber fractions.
\end{abstract}

Keywords: bovine, alkali, hydrolysis

\section{INTRODUÇÃO}

A cana-de-açúcar é um dos volumosos mais utilizados pelos pecuaristas por apresentar facilidade de estabelecimento, produção por vários anos, alta produtividade de matéria seca (MS) e valor nutritivo praticamente inalterado durante a seca. As pastagens, no período da seca, apresentam-se com baixa disponibilidade de forragem e deficientes em energia, proteína e minerais, ao passo que a cana madura, nessa época do ano, contém mais de $31 \%$ de sacarose (\%MS), o que a torna alternativa viável para alimentação de bovinos, nos países tropicais. A cana pode produzir mais de 200t de matéria verde (MV) por cada hectare (ha), e sua renovação torna-se necessária somente a partir do quarto ou do quinto ano. Apresenta boa aceitabilidade pelos animais, além de ter custo de

Recebido em 26 de agosto de 2010

Aceito em 10 de agosto de 2011

E-mail: mariana@cnpgl.embrapa.br 
produção relativamente baixo (Thiago, 2002). À medida que a cana amadurece, os teores de fibra em detergente neutro (FDN) e fibra em detergente ácido (FDA) reduzem-se, contrariamente ao observado para as demais forrageiras. Esse declínio pode ser explicado pela redução do percentual dos constituintes da parede celular em decorrência do acúmulo de carboidratos solúveis (Freitas et al., 2006).

Quando a forragem apresenta alto teor de FDN, como as forrageiras cortadas em idades avançadas, ou quando a fibra apresenta baixa digestibilidade, como a da cana-de-açúcar (Boin et al., 1987), podem-se utilizar substâncias químicas que visem melhorar a digestibilidade $\mathrm{e}$ a disponibilidade de nutrientes para os animais.

Estudos têm demonstrado que o tratamento de materiais fibrosos com álcali melhora sua digestibilidade. A cal micropulverizada, encontrada nas formas de $\mathrm{CaO}$ e $\mathrm{Ca}(\mathrm{OH})_{2}$, com baixos teores de magnésio $(\mathrm{Mg})$, dioxinas e furanos, certificados pelo Ministério da Agricultura, Pecuária e Abastecimento (MAPA) para alimentação animal, surge como alternativa segura e de baixo custo. A justificativa para emprego de álcali reside no fato de as ligninas de gramíneas serem particularmente susceptíveis ao ataque hidrolítico do álcali nas ligações covalentes do tipo éster entre a lignina e a parede celular (Van Soest, 1994).

O objetivo do presente trabalho foi avaliar a degradabilidade in situ da cana-de-açúcar tratada ou não com óxido de cálcio em diferentes porcentagens de inclusão, em novilhas leiteiras Holandês x Gir.

\section{MATERIAL E MÉTODOS}

O experimento foi realizado durante 11 dias, com um período de adaptação dos animais à dieta e às instalações por sete dias e um período de quatro dias para a coleta de amostras.

A variedade da cana-de-açúcar utilizada foi a RB 73-9735, e o plantio ocorreu em janeiro de 2006, em solo de mediana fertilidade. Essa variedade possui alta produtividade, estimada em 150t/ha, maturação mediana, florescimento raro, ausência de joçal, com época de colheita de junho a outubro. $\mathrm{O}$ experimento foi realizado de agosto a outubro de 2007, quando se fez o primeiro corte do canavial. A cana-de-açúcar utilizada apresentou grau Brix de 22. O cálculo das dietas experimentais basearam-se nos requisitos nutricionais do NRC (Nutrient..., 1989) com dietas isoproteicas.

Foram utilizadas cinco novilhas Holandês x Gir fistuladas no rúmen, mantidas em regime de confinamento, em sistema tipo tiestall, disponibilizando, assim, um cocho e um bebedouro (automático) para cada indivíduo. Foram avaliados quatro tratamentos com canade-açúcar tratada ou não com óxido de cálcio. Os tratamentos foram: cana-de-açúcar $(0,0)$; canade-açúcar $+0,5 \%$ de inclusão de óxido de cálcio $(0,5)$; cana-de-açúcar $+1,0 \%$ de inclusão de óxido de cálcio $(1,0)$; cana-de-açúcar $+2,0 \%$ de inclusão de óxido de cálcio $(2,0)$. Os tratamentos com inclusão de óxido de cálcio foram preparados 24 horas antes do início do processamento do material.

A degradabilidade in situ foi determinada utilizando-se sacos de náilon medindo 15 x $8 \mathrm{~cm}$, com malha de 50 micrômetros. Foi feita uma triplicata por tratamento e por tempo de incubação, sendo em cada saco colocados $5 \mathrm{~g}$ de cana-de-açúcar sem tratamento com óxido de cálcio ou cana-de-açúcar tratada com óxido de cálcio, moídos em peneira de $5 \mathrm{~mm}$ após secagem em estufa de ventilação forçada a $55^{\circ} \mathrm{C}$ por $72 \mathrm{~h}$. Antes da incubação, os sacos foram embebidos em água destilada por 10 minutos. As amostras foram inseridas no rúmen às $8 \mathrm{~h}$ da manhã e removidas às zero, seis, 12, 18, 24, 48, 72 e 96 horas após a inserção. Logo depois de retirada, os sacos foram lavados em água corrente, congelados e posteriormente secos em estufa ventilada a $55^{\circ} \mathrm{C}$ por $72 \mathrm{~h}$. Os resíduos dos tratamentos foram analisados para MS, FDN, FDA e MM, para determinação da MO.

Os animais foram alimentados com a dieta canade-açúcar $+0,5 \%$ de inclusão de óxido de cálcio + concentrado (Tab. 1), por ser a intermediária quanto à inclusão de $\mathrm{CaO}$ em relação aos tratamentos em que estavam sendo avaliadas as degradabilidades. Foi fornecido $1 \mathrm{~kg}$ de concentrado (Tab. 2) para cada $10 \mathrm{~kg}$ de cana-deaçúcar na $\mathrm{MN}$, no momento do arraçoamento. A dieta foi fornecida duas vezes ao dia, às oito e às $14 \mathrm{~h}$, em quantidades suficientes para que houvesse $15 \%$ de sobras. 
Tabela 1. Composição química da dieta dos animais experimentais, expressa em porcentagem da matéria seca (\%MS)

\begin{tabular}{lc}
\hline Nutriente & $\begin{array}{c}\text { Porcentagem de inclusão de } \\
\text { óxido de cálcio }\end{array}$ \\
\cline { 2 - 2 } & 0,5 \\
\hline MS* & 33,38 \\
MO & 85,30 \\
EE & 1,33 \\
CSDN & 43,33 \\
FDNcp & 32,02 \\
FDA & 19,53 \\
Lig & 3,39 \\
Cel & 16,14 \\
Hcel & 14,37 \\
PB & 8,63 \\
Cinzas & 14,70 \\
Ca & 1,19 \\
P & 0,18 \\
Ca/P & 6,58 \\
\hline MS
\end{tabular}

MS = matéria seca, *expresso em porcentagem da matéria natural; $\mathrm{MO}=$ matéria orgânica; $\mathrm{EE}=$ extrato etéreo; $\mathrm{CSDN}=$ carboidratos solúveis em detergente neutro; FDNcp = fibra insolúvel em detergente neutro corrigida para cinzas e proteína; FDA = fibra insolúvel em detergente ácido; $\mathrm{Lig}=$ ligninas; $\mathrm{Cel}=$ celulose; $\mathrm{HCel}=$ hemiceluloses; $\mathrm{PB}=$ proteína bruta; $\mathrm{Ca}=$ cálcio; $\mathrm{P}=$ fósforo; $\mathrm{Ca} / \mathrm{P}=$ relação cálcio e fósforo. 0,5: cana-de-açúcar $+0,5 \%$ de inclusão de óxido de cálcio + concentrado.
O concentrado da dieta apresentou a seguinte composição de ingredientes, em porcentagem da matéria natural: $50 \%$ de farelo de soja, $42 \%$ de fubá de milho, $5 \%$ de mistura de ureia e sulfato de amônio (9:1) e 3\% de mistura mineral. Na Tab. 2, está a composição da mistura mineral e do óxido de cálcio em micro e macrominerais.

Os parâmetros de degradação ruminal in situ da MS, MO, FDN e FDA da cana-de-açúcar foram estimados pelo processo iterativo do algoritmo Marquardt, com auxílio do procedimento para modelos não lineares (PROC NLIN) (SAS..., 2002). As estimativas dos parâmetros de degradabilidade ruminal da MS, MO, FDN e FDA foram obtidas para cada uma das cinco vacas, ajustando-se o modelo não linear descrito por Tomich e Sampaio (2004). Posteriormente, todos os parâmetros de degradação ruminal foram utilizados em análises de regressão (PROC REG) (SAS..., 2002) realizadas em função da porcentagem de inclusão de óxido de cálcio, 0,0; 0,5; 1,0 e 2,0\% da matéria natural da dieta, sendo incluídos nos modelos os efeitos de bloco (vaca), além dos termos linear e quadrático dos tratamentos. Efeitos foram considerados significativos quando $\mathrm{P}<0,05$.

Tabela 2. Composição mineral do óxido de cálcio e da mistura mineral, expressa em porcentagem da matéria seca para os macrominerais e em partes por milhão $(\mathrm{ppm})$ para os microminerais

\begin{tabular}{lcccc|cccc}
\hline & \multicolumn{4}{c}{ Macrominerais (\%) } & \multicolumn{4}{c}{ Microminerais (ppm) } \\
\cline { 2 - 9 } & $\mathrm{Ca}$ & $\mathrm{Mg}$ & $\mathrm{P}$ & $\mathrm{K}$ & $\mathrm{Cu}$ & $\mathrm{Zn}$ & $\mathrm{Fe}$ & $\mathrm{Mn}$ \\
\hline Mistura mineral & 9,6 & 1 & 8,7 & 0,08 & 1254 & 4228 & 5258 & 427 \\
Óxido de cálcio & 44,5 & 0,3 & 2,9 & 0,05 & 41 & 73 & 1388 & 128
\end{tabular}

$\mathrm{Ca}$ = cálcio; $\mathrm{Mg}$ = magnésio; $\mathrm{P}$ = fósforo; $\mathrm{K}$ = potássio; $\mathrm{Cu}=$ cobre; $\mathrm{Mn}$ = manganês; $\mathrm{Fe}$ = ferro e $\mathrm{Zn}$ = zinco.

As degradabilidades efetivas (DE) da MS, MO, FDN e FDA da cana-de-açúcar foram calculadas conforme proposto por Ørskov e McDonald (1979), utilizando-se valores de taxa de passagem ruminal de 2 e $5 \% / \mathrm{h}$ (Agricultural..., 1984), e aqueles estimados por Campos (2010) para cada tratamento.

\section{RESULTADOS E DISCUSSÃO}

Na Tab. 3, estão os valores de degradabilidades potencial e efetiva e as taxas de degradação da MS, MO, FDN e FDA da cana-de-açúcar e da cana-de-açúcar hidrolisada com porcentagens crescentes de óxido de cálcio em novilhas Holandês x Gir, e na Tab. 4, as regressões lineares obtidas dos valores das degradabilidades potencial e efetiva e taxas de degradação da MS e da MO. Os valores de degradabilidades potencial e efetiva e as taxas de degradação da MS e da MO aumentaram linearmente com o aumento de inclusão de $\mathrm{CaO}$. Esse aumento pode ter ocorrido em parte pelo escape do $\mathrm{CaO}$ dos sacos de náilon, em função de sua alta solubilidade. 
Tabela 3. Degradabilidades potencial (A) e efetiva (DE) e taxas de degradação (c) da matéria seca (MS), matéria orgânica (MO), fibra em detergente neutro (FDN) e fibra em detergente ácido (FDA) da cana-deaçúcar e da cana-de-açúcar hidrolisada com porcentagens crescentes de óxido de cálcio em novilhas Holandês x Gir

\begin{tabular}{|c|c|c|c|c|c|c|c|c|}
\hline \multirow[t]{2}{*}{ Parâmetro } & \multirow[t]{2}{*}{ Nutriente } & \multicolumn{4}{|c|}{$\begin{array}{l}\text { Porcentagem de inclusão de óxido de } \\
\text { cálcio } \\
\text { (\% da matéria natural) }\end{array}$} & \multicolumn{3}{|c|}{ Efeito (valor de P) } \\
\hline & & 0 & 0,5 & 1,0 & 2,0 & EPM & Linear & Quadrático \\
\hline $\mathrm{A}(\%)$ & MS & 79,4 & 81,3 & 81,9 & 85,2 & 0,28 & $<0,0001$ & NS \\
\hline $\mathrm{c}(\% / \mathrm{h})$ & MS & 3,12 & 3,30 & 3,87 & 4,28 & 2,18 & $<0,005$ & NS \\
\hline DE2 $(\%)$ & MS & 72,1 & 72,9 & 74,5 & 76,9 & 0,46 & $<0,0001$ & NS \\
\hline DE5 (\%) & MS & 67,8 & 68,0 & 69,6 & 71,2 & 0,61 & $<0,005$ & NS \\
\hline DEk1 (\%) & MS & 69,2 & ND & 72,5 & 74,8 & 0,32 & $<0,0001$ & NS \\
\hline $\mathrm{A}(\%)$ & MO & 79,3 & 80,0 & 80,7 & 83,0 & 0,26 & $<0,005$ & NS \\
\hline $\mathrm{c}(\% / \mathrm{h})$ & MO & 3,14 & 3,49 & 3,88 & 3,89 & 1,91 & $<0,05$ & NS \\
\hline DE2 $(\%)$ & MO & 71,0 & 71,5 & 72,7 & 74,1 & 0,42 & $<0,01$ & NS \\
\hline DE5 (\%) & MO & 66,2 & 66,3 & 67,5 & 68,3 & 0,51 & $<0,05$ & NS \\
\hline DEk1 (\%) & MO & 68,9 & ND & 70,9 & 71,6 & 0,37 & $<0,01$ & NS \\
\hline $\mathrm{A}(\%)$ & FDN & 46,7 & 48,5 & 46,2 & 46,6 & 0,72 & NS & NS \\
\hline $\mathrm{c}(\% / \mathrm{h})$ & FDN & 3,47 & 3,84 & 4,06 & 4,01 & 2,19 & NS & NS \\
\hline DE2 (\%) & FDN & 29,9 & 32,3 & 31,4 & 31,7 & 0,90 & NS & NS \\
\hline DE5 (\%) & FDN & 19,8 & 22,0 & 21,4 & 22,0 & 0,98 & NS & NS \\
\hline DEk1 (\%) & FDN & 24,4 & $\mathrm{ND}^{\mathrm{e}}$ & 24,1 & 24,8 & 0,91 & NS & NS \\
\hline $\mathrm{A}(\%)$ & FDA & 37,1 & 33,3 & 35,8 & 36,8 & 1,19 & NS & NS \\
\hline c $(\% / h)$ & FDA & 3,71 & 3,92 & 3,98 & 4,18 & 3,77 & NS & NS \\
\hline DE2 (\%) & FDA & 23,9 & 21,6 & 23,6 & 24,8 & 1,00 & NS & NS \\
\hline DE5 (\%) & FDA & 15,7 & 14,3 & 15,7 & 16,9 & 0,91 & NS & NS \\
\hline DEk1 (\%) & FDA & 18,1 & $\mathrm{ND}^{\mathrm{e}}$ & 18,3 & 20,0 & 1,10 & NS & NS \\
\hline
\end{tabular}

$\mathrm{EPM}=$ erro-padrão da média; $\mathrm{NS}=$ não significativo $(\mathrm{P}>0,05)$; DE calculadas utilizando taxas de passagem no rúmen de 2 e $5 \% / \mathrm{h}$, respectivamente, DE2 e DE5; DEk1 calculadas utilizando taxa de passagem estimada por Campos (2010); ND = não determinado.

Os valores de degradabilidades potencial, efetiva e as taxas de degradação da FDN e da FDA foram semelhantes entre os tratamentos, evidenciando que o $\mathrm{CaO}$ não interferiu nas ligações das Hcel e Cel a ponto de alterar os parâmetros avaliados. Ao comparar os valores encontrados neste estudo com os dados encontrados por Campos (2010) em ensaio de digestibilidade aparente com as mesmas dietas experimentais em vacas em lactação Holandês $\mathrm{x}$ Gir, verifica-se que os dados de degradabilidade potencial são muito semelhantes aos de digestibilidade aparente encontrados por Campos (2010) para a dieta sem adição de CaO. Para MS, os valores foram 79,4 e 77,29, para MO, 79,3 e 79,17 , e para FDN, 46,7 e 46,74, respectivamente, para degradabilidade potencial e digestibilidade aparente. São poucos os trabalhos publicados sobre a degradação ruminal da fibra da cana-de-açúcar, sendo mais frequentes dados de digestibilidade. 
Degradabilidade in situ da cana-de-açúcar...

Tabela 4. Regressões lineares obtidas dos valores das degradabilidades potencial (A) e efetiva (DE) e taxas de degradação (c) da matéria seca (MS), matéria orgânica (MO) da cana-de-açúcar e da cana-deaçúcar hidrolisada com porcentagens crescentes de óxido de cálcio, em novilhas Holandês x Gir

\begin{tabular}{lcccccc}
\multirow{2}{*}{ Variável } & Nutriente & \multicolumn{5}{c}{ Parâmetros da regressão linear $(\hat{\mathrm{Y}}=\mathrm{a}+\mathrm{bX})$} \\
\hline A $(\%)$ & MS & 79,52520 & 0,55171 & 2,79806 & 0,48157 & 0,6329 \\
c (\%/h) & MS & 0,03114 & 0,00204 & 0,00605 & 0,00178 & 0,3576 \\
DE2 (\%) & MS & 71,93480 & 0,51065 & 2,46994 & 0,44573 & 0,6099 \\
DE5 (\%) & MS & 67,59800 & 0,54126 & 1,81429 & 0,47245 & 0,4198 \\
DEk1 (\%) & MS & 69,38267 & 0,48432 & 2,77600 & 0,37515 & 0,7934 \\
A (\%) & MO & 79,11720 & 0,60980 & 1,87806 & 0,53228 & 0,3760 \\
c (\%/h) & MO & 0,03278 & 0,00189 & 0,00369 & 0,00165 & 0,1747 \\
DE2 (\%) & MO & 70,93840 & 0,57199 & 1,58411 & 0,49927 & 0,3230 \\
DE5 (\%) & MO & 66,11920 & 0,54708 & 1,10206 & 0,47753 & 0,1855 \\
DEk1 (\%) & MO & 69,13400 & 0,55188 & 1,36200 & 0,42748 & 0,3953 \\
\hline$\hat{Y}=v a r y y y y$
\end{tabular}

$\hat{\mathrm{Y}}=$ variável estimada; $\mathrm{X}$ = porcentagem de inclusão de óxido de cálcio (\% da matéria natural); a = estimativa do intercepto; DP (a) = erro-padrão da estimativa de "a"; b = coeficiente de regressão linear; DP (b) = erro-padrão da estimativa de "b"; r2 = coeficiente de determinação; DEs calculadas utilizando-se taxas de passagem no rúmen de 2 e 5\%/h, respectivamente, DE2 e DE5; DEk1 calculadas utilizando taxa de passagem estimada por Campos (2010).

Balieiro Neto et al. (2006) avaliaram o efeito da secagem das amostras sobre a degradabilidade in situ no rúmen das variedades de cana-de-açúcar IAC91-2195 e IAC86-2480 tratadas ou não com $\mathrm{CaO}$. Na variedade IAC86-2480, a degradabilidade da FDN com adição de $\mathrm{CaO}$ foi superior, independente da utilização de amostras secas ou úmidas, enquanto na IAC91-2195 foi superior apenas quando incubadas amostras úmidas. Os autores concluíram que a ausência de resposta da degradabilidade da matéria seca (DegMS) ao $\mathrm{CaO}$ em amostras secas deve-se provavelmente a um efeito de compensação entre a perda de CNF durante a secagem e o aumento da degradabilidade da fibra devido à hidrólise provocada pelo aditivo.

Aroeira et al. (1993), ao trabalharem com canade-açúcar mais ureia suplementada com farelo de algodão e farelo de arroz, encontraram taxa de degradação da MS da cana-de-açúcar de 3,2\%/h, sendo que grande parte do material foi rapidamente solubilizado $(55,2 \%)$, fração esta correspondente ao conteúdo celular. A parede celular foi muito pouco degradada, no rúmen, ao longo das 72 horas de degradação $(43,7 \%)$.

Com o intuito de investigar a degradabilidade ruminal da FDN da cana-de-açúcar tratada ou não com $1 \%$ (na $\mathrm{MN}$ ) de óxido de cálcio, utilizando-se vacas fistuladas no rúmen, Rabelo et al. (2009) avaliaram o efeito da cal, sob dois tempos de incubação ruminal (24 e 96 horas), sobre a degradabilidade da MS e da FDN. O tratamento da cana-de-açúcar com o $\mathrm{CaO}$ não foi efetivo estatisticamente $(\mathrm{P}<0,01)$ para assegurar melhoria na digestibilidade ruminal, sendo os valores após 24 horas de incubação de 42,75 e $43,12 \%$ para a MS e 18,40 e $25,16 \%$ para a FDN, para a cana-de-açúcar in natura e tratada, respectivamente, e após 96 horas, 56,17 e $57,91 \%$ para a MS e 40,92 e 41,40\% para a FDN, na cana-de-açúcar in natura e tratada, respectivamente.

Henriques et al. (2007), ao avaliarem a composição bromatológica e a degradação in situ da FDN da cana-de-açúcar tratada com óxido de cálcio em diferentes doses de inclusão $(0 ; 0,5$; $1,0$ e $1,5 \%)$ e tempos de armazenagem $(0 ; 24 ; 48$ e 72 horas), inferiram que a inclusão de $\mathrm{CaO}$ produz hidrólise da parede celular, resultando em menores teores de FDN, FDA e lignina. Nas condições testadas, a cana-de-açúcar pode ser armazenada por até 72 horas. Os autores concluíram que a inclusão de $\mathrm{CaO}$ aumenta a fração potencialmente degradável e a taxa de degradação ruminal da FDN. 
Carmo et al. (2001), ao estudarem a degradação da cana-de-açúcar em dietas com diferentes fontes de proteína degradável, encontraram taxa de degradação $(\mathrm{kd})$ para a MS de $3,34 \% / \mathrm{h}$, valor semelhante ao encontrado no presente estudo.

\section{CONCLUSÕES}

$\mathrm{O}$ aumento do nível de inclusão de $\mathrm{CaO}$ em dietas à base de cana-de-açúcar aumenta linearmente a degradabilidade in situ da MS e da MO e não altera a degradabilidade in situ das frações fibrosas, em novilhas leiteiras Holandês x Gir.

\section{REFERÊNCIAS BIBLIOGRÁFICAS}

AGRICULTURAL RESEARCH COUNCIL - ARC. The Nutrient Requirements of Ruminant Livestock. London: CAB, Suppl. 1, 1984. 45p.

AROEIRA, L.J.M.; FIGUEIRA, D.G.; RODRIGUEZ, N.M. et al. Degradabilidade in situ dos nutrientes da cana-de-açúcar e do farelo de algodão em bovinos alimentados com farelo de algodão e cana-de-açúcar adicionada de três níveis de ureia. Arq. Bras. Med. Vet. Zootec., v.45, p.221-233, 1993.

BALIEIRO NETO, G.; LIMA, M.L.P.; REIS, R.A. et al. Determinação da degradabilidade ruminal in situ com amostras secas ou úmidas de duas variedades de cana-de-açúcar tratadas ou não com óxido de cálcio. In: REUNIÃO ANUAL DA SOCIEDADE BRASILEIRA DE ZOOTECNIA, 43., 2006, João Pessoa. Anais... João Pessoa: SBZ, 2006. (CD-ROM).

BOIN, C.; MATTOS, W.R.S.; D'ARCE, R.D. Canade-açúcar e seus subprodutos na alimentação de ruminantes. In: PARANHOS, S.B. (Coord.). Cana-deaçúcar: cultivo e utilização. Campinas: Fundação Cargill, 1987. v.2, p.805-850.

CAMPOS, M.M. Cana-de-açúcar tratada ou não com óxido de cálcio na alimentação de fêmeas bovinas leiteiras. 2010. 129f. Tese (Doutorado) - Escola de Veterinária, Universidade Federal de Minas Gerais, Belo Horizonte.

CARMO, C.A.; BERCHIELLI, T.T.; ANDRADE, P. Degradabilidade da matéria seca e fibra em detergente neutro da cana-de-açúcar (Saccharum spp) com diferentes fontes de proteína. Rev. Bras. Zootec., v.30, p.2126-2133, 2001.
FREITAS, A.W.P.; PEREIRA, J.C.; ROCHA, F.C. et al. Características da silagem de cana-de-açúcar tratada com inoculante bacteriano e hidróxido de sódio e acrescida de resíduo da colheita de soja. Rev. Bras. Zootec., v.35, p.48-59, 2006.

HENRIQUES, L.T.; VALADARES FILHO, S.C.; DETMANN, E. et al. Composição química e degradação in situ da fibra em detergente neutro da cana-de-açúcar tratada com óxido de cálcio em diferentes doses de inclusão e tempos de armazenagem. In: CONGRESSO BRASILEIRO DE ZOOTECNIA, 17., 2007, Londrina, PR. Anais... Londrina: UEL/ABZ, 2007. (CD-ROM).

NUTRIENT requirements of the dairy cattle. 6. ed. Washington, DC: National Academy of Sciences, 1989. $158 \mathrm{p}$.

ØRSKOV, E.R.; McDONALD, I. The estimation of protein degradability in the rumen from incubation measurements weighted according to rate of passage. J. Agric. Sci., v.92, p.499-503, 1979.

RABELO, F.H.S.; SALVADOR, F.M.; REZENDE, A.V. et al. Efeito da hidrólise da cana-de-açúcar com óxido de cálcio sobre a degradabilidade ruminal da fibra em detergente neutro. In: REUNIÃO ANUAL DA SOCIEDADE BRASILEIRA DE ZOOTECNIA, 46., 2009, Maringá. Anais ... Maringá: SBZ, 2009. (CD-ROM).

SAS Institute Inc. SAS ${ }^{\circledR}$ User's Guide: Statistics, Version 5 Edition. Cary, NC: SAS Institute Inc., 2002.

THIAGO, L.R.L.S.; VIEIRA, J.M. Cana-de-açúcar: uma alternativa de alimento para a seca. Campo Grande: EMBRAPA-CNPGC, 2002. 5p. (EMBRAPACNPGC. Comunicado Técnico, 73).

TOMICH, T.R.; SAMPAIO, I.B.M. A new strategy for the determination of forage degradability with an in situ technique through the use of one fistulated ruminant. J. Agric. Sci., v.142, p.589-593, 2004.

VAN SOEST, P.J. Nutricional ecology of the ruminant. 2. ed. Ithaca: Cornell University, 1994. 476p. 